\title{
Monochlorophenols Degradation by UV/Persulfate Is Immune to the Presence of Chloride: Illusion or Reality?
}

Changling Fang ${ }^{\mathrm{a}}$, Xiaoyi Lou ${ }^{\mathrm{a}}$, Ying Huang ${ }^{\mathrm{a}}$, Min Feng ${ }^{\mathrm{a}}$, Zhaohui Wang ${ }^{\mathrm{a}, \mathrm{b}, *}$, Jianshe $\mathrm{Liu}^{\mathrm{a}}$

${ }^{a}$ State Environmental Protection Engineering Center for Pollution Treatment and Control in Textile Industry, College of Environmental Science and Engineering, Donghua University, Shanghai, 201620, China

${ }^{\mathrm{b}}$ International Centre for Balanced Land Use (ICBLU), The University of Newcastle, Callaghan, NSW 2308, Australia

Tel: +86-21-67792557; Fax: +86-21-67792522

E-mail: zhaohuiwang@dhu.edu.cn (Z.Wang) 


\section{ABSTRACT}

The efficiency and, accordingly, the success of the advanced oxidation processes (AOPs) has generally been evaluated on the basis of degradation kinetics. In practice, chloride in saline wastewater is often found to inhibit degradation processes. Therefore its highly desirable to develop more effective processes which are not affected by chloride. In this study, no significant interference of chloride with monochlorophenols (MCPs, e.g. 2-CP, 3-CP and 4-CP) degradation by the UV photoactivated persulfate (UV/PS) process has been observed. This indicated the "illusion" that the UV/PS process might have been an appropriate technology working under saline conditions. To further evaluate its applicability, the generation of reaction intermediates, of adsorbable organic halogen (AOX) accumulation and of acute toxicity of MCPs in the UV/PS system were examined. In reality, several aromatic chlorinated compounds (number of chlorine atoms $\geq 2$ ), such as dichlorophenols and 2,3,5,3',5'-pentachloro-biphenyl, were identified and quantified. An accumulation and relative increase of AOX with reaction time was observed in the UV/PS/Cl system. The acute toxicity tests with Photobacterium phosphoreum indicated that the inhibition effect of UV/PS reactions increased with reaction time regardless of the presence of chloride or not. The results of this study might be helpful for assessing the PS-based technologies for saline wastewater treatment.

Keywords: UV/persulfate; monochlorophenols; chloride ion; AOX formation; acute toxicity 


\section{Introduction}

Advanced oxidation processes (AOPs), based on the formation of very reactive species such as hydroxyl $\left(\mathrm{HO}^{\circ}\right)$ or sulfate $\left(\mathrm{SO}_{4}{ }^{--}\right)$radicals, have been applied successfully to the treatment of industrial wastewater containing recalcitrant compounds [1-4]. However, industrial effluents often contain large amounts of chloride ions, which are known to be important $\mathrm{HO}^{\circ}$ and $\mathrm{SO}_{4}{ }^{--}$scavengers [4-8]. Chloride ions upon reaction with $\mathrm{HO}^{\circ}$ or $\mathrm{SO}_{4}{ }^{--}$radicals, form reactive chlorine species $\left(\mathrm{Cl}_{2}{ }^{-}, \mathrm{Cl}^{\bullet}\right.$ and $\left.\mathrm{ClOH}^{-}\right)$, which may have a significant influence on the overall treatment efficiency of radical-based AOPs [7-9].

Previous investigations have focused on the impact of $\mathrm{Cl}^{-}$ions on the performance of different AOPs [6,10-13]. However, in most cases the applicability of the selected AOPs was evaluated by assessing the degradation efficiency in saline wastewater. Since $\mathrm{HO}^{\circ}$ could oxidize $\mathrm{Cl}^{-}$ions to generate less reactive chlorine species $\left(\mathrm{Cl}_{2} / 2 \mathrm{Cl}^{-}\right.$ $\left.(1.36 \mathrm{~V}) ; \mathrm{HOCl} / \mathrm{Cl}^{-}(1.48 \mathrm{~V})\right)[8]$, the involvement of $\mathrm{Cl}^{-}$ions would inhibit $\mathrm{HO}^{\circ}-$ based radical chain reactions. Thus, the overall efficiency of the various $\mathrm{HO}^{\circ}$-based AOPs would be reduced. Therefore, $\mathrm{HO}^{\circ}$-based AOPs are not suitable for the treatment of salt-rich wastewater. Similar to the $\mathrm{HO}^{\circ}$-based AOPs, chloride ions in saline wastewater might retard the degradation rate of the target pollutants during $\mathrm{SO}_{4}{ }^{-}$-based AOPs, because chlorine radicals may also be generated by interaction between $\mathrm{SO}_{4}{ }^{--}$and $\mathrm{Cl}^{-}$ions. Chan et al [14] have reported that the reaction rate for atrazine removal was reduced by $12-28 \%$ in the presence of $\mathrm{Cl}^{-}(0-34.2 \mathrm{mM})$ for a cobalt-mediated activation of the peroxymonosulfate (Co/PMS) process. However, our recent work indicated that increased concentrations of chloride $(>50 \mathrm{mM})$ in a PMS-based AOP could enhance the decoloration rate of an azo dye-AO7. In addition, further investigations found that $\mathrm{Cl}_{2}{ }^{--}, \mathrm{Cl}^{\bullet}$ and $\mathrm{ClOH}^{*-}$ were capable of producing 
some polychlorinated intermediates, resulting in an undesirable increase of adsorbable organic halides (AOX) $[15,16]$. Therefore, it is rather inadequate to assess the effect of chloride ions on AOP performance by the removal efficiency of model pollutants only. On the other side, it is urgent to find an effective way to treat hypersaline wastewater, besides more accurate parameters are needed to evaluate the effect of $\mathrm{Cl}^{-}$ ions in a radical-based AOP treatment.

Persulfate $\left(\mathrm{S}_{2} \mathrm{O}_{8}{ }^{2-}\right.$, PS) can be activated by UV irradiation [17], heat [18], ultrasound [19], transition metal ions [20] or $\mathrm{H}_{2} \mathrm{O}_{2}$ [21] to produce $\mathrm{SO}_{4}{ }^{--}$for the oxidation of various organic pollutants. However, heating the contaminated wastewater to activate persulfate during treatment is economically not feasible. Also an activation by transition metal ions might result in increased metal toxicity and secondary pollution. An UV photo-activated persulfate (UV/PS) process is a nonpolluting, economically feasible way to activate persulfate and, consequently to degrade the target organic pollutants [22-24].

AOX is an important parameter that serves to assess the total amount of organically bound chlorine and can be expressed in microgram per liter $(\mu \mathrm{g} / \mathrm{L})$ of chloride ions in wastewater. Previous studies involving the application of different AOPs, such as $\mathrm{UV} / \mathrm{H}_{2} \mathrm{O}_{2}$, Fenton processes, $\mathrm{UV} / \mathrm{TiO}_{2}$ and $\mathrm{PMS}$-based AOP, reported the removal/accumulation of AOX $[5,16,25,26]$. The AOX values significantly decreased with reaction time during 4-chlorophenol degradation by $\mathrm{HO}^{\circ}$-based AOPs in the absence of $\mathrm{Cl}^{-}$ions as Peternel et al presented [25]. The result is consistent with the results of the degradation kinetics. However, our recent study indicated that the yield of $\mathrm{AOX}$ were also enhanced with the increasing $\mathrm{Cl}^{-}$concentration during PMS-based AOP [16]. Thus, more attention is needed for the accumulation of chlorinated aromatic intermediates, since some of them may be more toxic than their 
parent compounds. All in all, it seems to be reasonable to examine the correlation between the accumulation of $\mathrm{AOX}$ and the toxicity of the reaction medium, when evaluating the applicability of a new AOP technology.

In the present study 2-chlorophenol (2-CP), 3-chlorophenol (3-CP) and 4chlorophenol (4-CP) were selected as model chlorophenols (CPs), because of their known environmental hazard and wide occurrence in different kinds of industrial effluents $[25,27]$. The degradation kinetics and AOX formation in an UV/PS system were evaluated with the addition of chloride ions. The transformation of the three monochlorophenols (MCPs) into aromatic oxidation products was also investigated under selected treatment conditions.

\section{Experimental section}

\subsection{Materials}

2-CP (> 99.0\%), 3-CP (> 98.0\%) and 4-CP (> 98.0\%) were supplied by TCI (Shanghai, China). Potassium persulfate $\left(\mathrm{K}_{2} \mathrm{~S}_{2} \mathrm{O}_{8},>99.0 \%\right)$ was purchased from Alfa Aesar. Methanol (HPLC grade) was obtained from Sigma-Aldrich. $\mathrm{NaCl}, \mathrm{NaNO}_{2}$, $\mathrm{NaNO}_{3}$ and $\mathrm{Na}_{2} \mathrm{SO}_{3}$ were at least analytical grade and used as received without further purification. Barnstead UltraPure water $(18.2 \mathrm{M} \Omega \cdot \mathrm{cm})$ was used throughout the analytical experiments. Stock solutions of all chemicals were always freshly prepared.

\subsection{Experimental Procedures}

All the photochemical experiments for MCP degradation were conducted in an XPA-7 photochemical reactor supplied by Xujiang Electromechanical Plant, Nanjing, China. One $100 \mathrm{~W}$ medium-pressure mercury vapor lamp $\left(\lambda_{\max }=365 \mathrm{~nm}\right)$ was used as the light source in a water cooled borosilicate glass immersion well. The 
photochemical reactions were carried out at room temperature without $\mathrm{pH}$ control. Other parameters of the photochemical instrument are detailed in our previous publication [28]. All experiments were performed in continuously stirred $50 \mathrm{~mL}$ quartz tubes. The reaction solutions were always freshly prepared with an initial $\mathrm{pH}$ of $(4.00 \pm 0.05)$ (adjusted with $\mathrm{NaOH}$ and $\left.\mathrm{H}_{2} \mathrm{SO}_{4}\right)$ unless otherwise specified, and the $\mathrm{pH}$ was not controlled during the reaction process. Samples were taken from the solution for analysis at specific time intervals and immediately quenched in a 1:1 volumetric ratio with methanol (for HPLC analysis) or $0.2 \mathrm{M} \mathrm{NaNO}_{2}$ (for GC-MS analysis). The oxidation of MCPs by PS alone was found to be negligible in control experiments in the dark.

\subsection{Analysis}

The concentrations of the MCPs were measured by an Agilent 1100 highperformance liquid chromatography (HPLC) instrument (UV-vis detector) with a GL Inertsil ODS-SP column $(4.6 \mathrm{~mm} \times 250 \mathrm{~mm}, 5 \mu \mathrm{m})$ maintained at $30{ }^{\circ} \mathrm{C}$. The mobile phase was methanol/water $(65 / 35(\mathrm{v} / \mathrm{v}))$ with a flow rate of $1.0 \mathrm{~mL} / \mathrm{min}$. The detector wavelength was set at $272 \mathrm{~nm}$.

The organic intermediates formed during MCP degradation were identified by gas chromatography-mass spectrometry (GC-MS, Agilent 7890A-5975C, USA). Samples were pretreated by liquid-liquid extraction and silylation methods to extract and concentrate compounds with different polarity and volatility (see details in supporting information). The oven temperature was programmed to begin under isothermal conditions at $80{ }^{\circ} \mathrm{C}$ for $6 \mathrm{~min}$, then rise to $180{ }^{\circ} \mathrm{C}$ at a rate of $4{ }^{\circ} \mathrm{C} / \mathrm{min}$ and remain constant at $180{ }^{\circ} \mathrm{C}$ for $10 \mathrm{~min}$. The injection port and ion source temperatures were held at $280{ }^{\circ} \mathrm{C}$ and $230{ }^{\circ} \mathrm{C}$, respectively. The mass scan range was $10-500 \mathrm{~m} / \mathrm{z}$. The 
mass spectra were searched and compared through the database of National Institute of Standards and Technology 08 (NIST08) library for characterization (the matching quality between the experimental data and the database is more than 90\%). Their evolution was determined by tracking the changes in peak areas of the individual oxidation products with respect to treatment time. The minimum peak area was set at 5000.

AOX present in MCP solution were analyzed by an AOX analyzer (multi X 2500, Jena, Germany) using a column adsorption method according to the European Standard EN 1485 H14 [29]. The detection of AOX ranged from $1 \mu \mathrm{g}$ to $100 \mu \mathrm{g}$ (expressed as the absolute content of chloride).

The acute toxicity of a MCP solution after UV/PS treatment for different time periods was evaluated with a Model Toxicity Analyzer (DXY-3, Institute of Soil Science, Chinese Academy of Sciences, Nanjing, China). It is a bioassay based on the inhibition of bioluminescence emitted by the luminescent bacterium Photobacterium phosphoreum (T3 mutation). The bioluminescence was measured after 15 min of exposure at $(20 \pm 1)^{\circ} \mathrm{C}[2]$. To ensure the accuracy, each sample was tested in duplicate. Luminescence inhibition in percent was used to quantify the effect of MCPs and their metabolites on Photobacterium phosphoreum. The inhibition was calculated according to Eq. (1) [30]. Generally, an increased inhibition means that the reaction mixture is more toxic [31].

$$
\text { Inhibition }(\%)=\times 100 \%
$$

where $\mathrm{L}_{\text {sample }}$ is the luminescence of the sample aliquot taken at each time interval from the AOP reaction assay, and $\mathrm{L}_{\text {blank }}$ is the luminescence of pure water (replacing the sample).

\section{Results and discussion}




\subsection{Degradation kinetics}

With a UV/PS process in a saline MCP solution, direct photolysis and oxidation of MCPs by $\mathrm{HO}^{\circ}$ and $\mathrm{SO}_{4}{ }^{-}$radicals and reactive chlorine radicals are the two pathways for MCP degradation. The preliminary UV photolysis experiments indicate insignificant effects of chloride on the rates of direct photolysis of MCPs (Fig. S1). Fig. 1 shows the effects of chloride on MCP degradation by the UV/PS process. Unexpectedly, no apparent inhibitory effect of chloride was observed within a broad range of chloride concentrations $(0-300 \mathrm{mM})$. Values for rate constant calculated as pseudo-first-order kinetics were very close at various chloride dosages. In the absence of $\mathrm{Cl}^{-}$, the removal rates for $2-\mathrm{CP}, 3-\mathrm{CP}$ and $4-\mathrm{CP}$ were $85 \pm 2.2 \%, 91 \pm 0.7 \%$ and 90 $\pm 0.8 \%$ after $60 \mathrm{~min}$ of reaction, resulting in rates of $0.03104 \pm 0.00096 \mathrm{~min}^{-1}$, $0.03334 \pm 0.00096 \mathrm{~min}^{-1}$ and $0.03681 \pm 0.00211 \mathrm{~min}^{-1}$, respectively. When the concentration of $\mathrm{Cl}^{-}$amounted to $300 \mathrm{mM}, 89 \pm 0.3 \%, 87 \pm 3.3 \%$ and $100 \%$ of $2-\mathrm{CP}$, 3-CP and 4-CP had been degraded after $60 \mathrm{~min}$, respectively. The rate constants were $0.02887 \pm 0.00080 \mathrm{~min}^{-1}, 0.02619 \pm 0.00167 \mathrm{~min}^{-1}$, and $0.04685 \pm 0.00067 \mathrm{~min}^{-1}$ for 2-CP, 3-CP and 4-CP, respectively.

These results are consistent with previous investigations. Liang et al [32] reported that chloride did not affect the degradation rate of trichloroethylene in the PS oxidation process, if chloride levels were below $200 \mathrm{mM}$. Yang et al [22] also observed a minor influence of halides on the degradation efficiency of contaminants by the UV/PS AOP. Effects of $\mathrm{Cl}^{-}$on the degradation kinetics of PS-based AOPs were different from PMS-based AOPs. A dual effect of chloride ions on the degradation kinetics of organic pollutants was observed for PMS-based AOPs. This may due to the fact that $\mathrm{Cl}^{-}$ions alone can not activate PS. However, they can directly react with PMS to generate a series of reactive chlorination agents $\left(\mathrm{Cl}_{2} / \mathrm{HOCl}\right)$, as 
previous literature suggested [16]. Another explanation is that $\mathrm{SO}_{4}{ }^{--}$could oxidize $\mathrm{Cl}^{-}$ ions and generate a $\mathrm{Cl}^{\circ}$ radical (Eq. (2)), which subsequently might produce a $\mathrm{HO}^{\circ}$ through $\mathrm{ClOH}^{--}$(Eqs. (3) and (4)). Also, the formation of chlorate $\left(\mathrm{ClO}_{3}{ }^{-}\right)$by the $\mathrm{SO}_{4}{ }^{--}$radical is possible to happen at acidic $\mathrm{pH}(<5$, Table $\mathrm{S} 1)$ during the depletion of MCPs [33]. $\mathrm{Cl}_{2}{ }^{--}$could be formed according to Eq. (5), which may recombine to further yield $\mathrm{Cl}_{2}$ and $\mathrm{Cl}^{-}$. Furthermore, $\mathrm{Cl}_{2}$ may hydrolyze to generate $\mathrm{HOCl} / \mathrm{OCl}^{-}$, which may be oxidized by $\mathrm{HO}^{\circ}$ or $\mathrm{Cl}^{\circ}$ giving rise to $\mathrm{ClO}_{3}{ }^{-}$. The reactive species formed in the presence of $\mathrm{Cl}^{-}$are often less reactive than the $\mathrm{SO}_{4}{ }^{--}$radical. Thus, the presence of $\mathrm{Cl}^{-}$would reduce the oxidation capacity by scavenging $\mathrm{SO}_{4}{ }^{-}$. The generation of $\mathrm{Cl}^{\cdot}, \mathrm{ClOH}^{--}$and chlorate, inter-conversion of $\mathrm{SO}_{4}{ }^{--}$into $\mathrm{HO}^{\circ}$ may be accelerated with the increasing $\mathrm{Cl}^{-}$concentration $[22,33]$

$$
\begin{aligned}
& \mathrm{Cl}^{-}+\mathrm{SO}_{4}{ }^{-} \leftrightarrow \mathrm{Cl}^{\cdot}+\mathrm{SO}_{4}{ }^{2-} \\
& \mathrm{Cl}^{\bullet}+\mathrm{H}_{2} \mathrm{O} \leftrightarrow \mathrm{ClOH}^{--}+\mathrm{H}^{+} \\
& \mathrm{ClOH}^{--} \leftrightarrow \mathrm{HO}^{\cdot}+\mathrm{Cl}^{-} \\
& \mathrm{Cl}^{\cdot}+\mathrm{Cl}^{-} \leftrightarrow \mathrm{Cl}_{2}{ }^{--}
\end{aligned}
$$

\subsection{Identification of chlorinated intermediates}

In order to further evaluate the applicability of UV/PS AOP, the main oxidation intermediates were identified by GC-MS. Table 1 summarizes the tentatively identified products from the oxidation process.

In a chloride-rich environment $(300 \mathrm{mM})$ during the UV/PS process (i.e. $\mathrm{UV} / \mathrm{PS} / \mathrm{Cl}$ ), a large amount of chlorinated intermediates was detected at an initial MCP concentration of $0.2 \mathrm{mM}$. More products were obtained from 4-CP degradation than during the degradation of 2-CP and 3-CP (Fig. S2). The major degradation intermediates detected from the UV/PS/Cl system (Table 1) were similar to those identified in other oxidation processes such as photocatalysis [34] or the Co/PMS 
system [4,15]. Specifically, the chlorinated compounds formed during 4-CP degradation (Fig. S3-S13, Fig. S17-S33) can be grouped mainly into five types: (1) dichlorophenols compounds, like 2,4-dichlorophenol, 2,5-dichlorophenol, 2,6dichlorophenol; (2) a trichlorophenol like 2,4,6-trichlorophenol; (3) a p-benzoquinone compound like 2-chloroquinone; (4) chlorobenzenediol compounds like 4chlorobenzene-1,2-diol, 2,5-dichloro-benzene-1,4-diol, 4,6-dichloro-benzene-1,3-diol, 3,6-dichloro-benzene-1,2-diol, 2-chlorobenzene-1,4-diol, 2-chlorobenzene-1,3-diol; (5) a C-C coupling of a chlorophenoxy compound like 2,3,5,3',5'-pentachlorobiphenyl. It should be noted that most of them were detected during the degradation of 4-CP in the presence of chloride, except for 2,3,5,3',5'-pentachloro-biphenyl. This difference found in chlorinated intermediates may be related to the chlorine position in the MCPs. Various previous investigations have indicated that the chlorine positions on chlorophenol isomers play an important role on the kinetics of chlorophenol photo-degradation [27,35].

The reaction intermediates of three MCPs in the absence of chloride were also identified (Table 1, Fig. S14-S16, Fig. S34-S49). The chlorinated intermediates identified for 4-CP degradation can be classified into three groups: (1) dichlorophenols compounds including 2,3-dichlorophenol, 2,5-dichlorophenol, 2,6dichlorophenol; (2) a trichlorophenol, 2,4,5-trichlorophenol; (3) a C-C coupling of a chlorophenoxy compound, 2,3,5,3',5'-pentachloro-biphenyl.

Proposed reactions pathways for the oxidation of 4-CP are shown in Fig. 2, based on the products identified and previous literature $[15,25,30,36]$. The first step of the reaction mechanism for the degradation of 4-CP involves two different pathways. Pathway I leads to the formation of hydroquinone, 1,4-benzoquinone and 4chlorocatechol. Previous reports have shown that the electron transfer and hydrogen 
abstraction are assumed to be the first step of the sulfate radical attack during the oxidation of 4-chlorophenol [36]. A sulfate radical mediated attack on a benzene ring leads to the formation of carbon centered radicals via electron transfer from the organic compound to the sulfate radical [4]. The hydrolysis of the radical cation formed after sulfate elimination results in the formation of hydroxylated radical products, and then further reaction with $\mathrm{O}_{2}$ gives rise to the stable intermediates hydroquinone and 4-chlorocatechol. 1,4-benzoquinone is then produced via hydrogen abstraction from hydroquinone. Pathway II leads to the formation of chlorinated aromatic intermediates by nucleophilic addition of chlorine radicals to the aromatic ring. In a chlorine-rich environment, reactive chlorine species were generated by a $\mathrm{SO}_{4}{ }^{-}$radical scavenging a chloride ion [6-10]. The resulting chlorine radicals $\mathrm{Cl}^{\circ} / \mathrm{Cl}_{2}{ }^{-}$ could react with 4-CP and its derivatives leading to the formation of chlorinated intermediates as shown in Fig. 2. The cation radical of 4-CP was produced through the addition and, then, elimination of $\mathrm{SO}_{4}{ }^{--}$. Since the para position is occupied by chloride, chlorination easily occurs at the ortho position $(\mathrm{C} 2, \mathrm{C} 6)$ to the $\mathrm{OH}$ group (e.g. 2,4-dichlorophenol, 2,4,6-trichlorophenol). It is noted that 2,4,5-trichlorophenol and 2,5-dichloro-benzene-1,4-diol were also formed in the presence of $300 \mathrm{mM} \mathrm{Cl}^{-}$. Meanwhile, 2-chlorobenzoquinone is formed by chlorination in the ortho position of 1,4-benzoquinone.

In particular, the detection of 2,3,5,3',5'-pentachloro-biphenyl among the degradation products of 2-CP and 3-CP suggests another possible reaction mechanism, which would involve the formation of the C-C coupling of a chlorophenoxy intermediate compound. The identification of aromatic chlorinated compounds (number of chlorine atoms $\geq 2$ ) during the MCPs oxidation via the UV/PS/Cl process supports a reaction mechanism involving a $\mathrm{SO}_{4}{ }^{-}$radical addition, chlorine radical 
formation and a subsequent chlorination. Several chlorinated products were also formed in the absence of $\mathrm{Cl}^{-}$. This was a result of the chloride atoms in the benzene ring, which were released due to the $\mathrm{SO}_{4}{ }^{--}$attack, and then became oxidized to the radical form by sulfate radicals. The chlorine radicals would react with MCPs or their intermediates to generate some chlorinated products [15,37].

\subsection{Evolution of oxidation products}

A semi-quantitative analysis by GC-MS was performed in order to further evaluate the transformation mechanisms of MCPs and their oxidation products. Because not all standards of the transformation byproducts are commercially available, accurate quantification of all products is too difficult. Instead, an evaluation of the product abundance was possible only on the basis of quantification by the peak area. Fig. 3 shows time courses of MCP degradation and their oxidation byproducts in a UV/PS/Cl or in a UV/PS system. All MCPs were almost completely degraded after 120 min of treatment. Correspondingly, several toxic chlorinated intermediates were gradually generated.

As shown in Fig. 3, in the presence of $\mathrm{Cl}^{-}$most of the detected chlorinated intermediates increased with the reaction time and decreased gradually in the later stage. For example, the product 2,3,5,3',5'-pentachloro-biphenyl was detected at the beginning ( $5 \mathrm{~min}$ ) and reached its maximum after $60 \mathrm{~min}$ of reaction time, afterwards the concentration decreased (Fig. 3a and 3b). Three dichlorophenols, such as 2,3dichlorophenol, 2,4-dichlorophenol, 2,5-dichlorophenol, were identified during the UV/PS/Cl oxidation of 4-CP (Fig. 3c). 2,4-dichlorophenol and 2,5-dichlorophenol immediately reached a maximum concentration within $5 \mathrm{~min}$ followed by a rapid decrease. Both 2,4-dichlorophenol and 2,5-dichlorophenol were completely degraded after 90 min of treatment. Much later than the formation of the former two products, 
the signal of 2,3-dichlorophenol increased and achieved its peaks after $90 \mathrm{~min}$. The detection of dichlorinated products during 4-CP degradation via the UV/PS/Cl process further supports the proposed mechanism shown in Fig. 2. However, an increased peak area for 2,3,5,3',5'-pentachloro-biphenyl was observed for the 2-CP and 3-CP degradation highlighting the prevalence of the C-C coupling mechanism for the UV/PS/Cl system. Some other products listed in Table 1 are short-lived and were promptly converted into stable substances. The peak areas of these were low, thus, they are negligible. Therefore, the evolution of these byproducts is not given in Fig. 3.

For comparison, evolution of the major byproducts from MCP degradation in the absence of $\mathrm{Cl}^{-}$is provided in Fig. 3 (a', b', c'). MCPs disappeared completely within 120 min of treatment time in the absence of $\mathrm{Cl}^{-}$. The involvement of polychlorinated intermediates (such as 2,3,5,3',5'-pentachloro-biphenyl and 2,4-dichlorophenol) indicates that a treatment of MCPs by the UV/PS process leads to the release of $\mathrm{Cl}^{-}$, which in turn can react with $\mathrm{SO}_{4}{ }^{--}$radicals to produce chlorine radicals. The latter can react with organic compounds in substrate transformation reactions[15]. However, since the release of $\mathrm{Cl}^{-}$was low, only little amounts of chlorinated byproducts occurred in the absence of $\mathrm{Cl}^{-}$ions.

\subsection{AOX formation}

All experimental results obtained from GC-MS measurements show that chlorinated organic intermediates are generated, when certain concentrations of chloride were present in the UV/PS system. The formation and accumulation of chlorinated oxidation intermediates might be more toxic than the parent compounds [38]. The AOX value was measured, in order to assess the total amount of organically bound chlorine. Thus for comparison, the formation of $\mathrm{AOX}$ in the $\mathrm{UV} / \mathrm{H}_{2} \mathrm{O}_{2}$ process was also investigated in this study. Fig. 4 presents results of AOX measurements 
under different experimental conditions. The initial AOX value at $t=0$ min represents the sole contribution of the substrates.

In the UV/PS system, without any chloride present, AOX levels decreased gradually with reaction time due to the degradation of the MCPs. In a chloride-rich environment, the AOX values dropped within the first 15 min of reaction time, then decreased slowly (Fig. 4a, 4b), the latter was even followed by a dramatic increase during UV/PS oxidation of 4-CP (Fig. 4c). After 180 min treatment, the AOX amounts in the mixture solutions were about $48 \pm 0.5 \%, 48 \pm 2.7 \%$ and $26 \pm 0.6 \%$ in the absence of $\mathrm{Cl}^{-}$, respectively. These AOX amounts increased to $91 \pm 1.9 \%, 71 \pm$ $2.8 \%$ and $91 \pm 3.0 \%$ in the presence of $300 \mathrm{~m} \mathrm{M} \mathrm{Cl}^{-}$. Overall, there was a general trend of a relatively increased formation of $\mathrm{AOX}$ during the degradation of 2-CP, 3$\mathrm{CP}$ or 4-CP in the presence of $\mathrm{Cl}^{-}$.

For the $\mathrm{UV} / \mathrm{H}_{2} \mathrm{O}_{2}$ process, the effect of chloride on the degradation kinetics and organic products have been reported in previous studies [5,19,39]. Yuan et al [35] found that the photooxidative decoloration and mineralization extent of Acid Orange 7 (AO7) was dramatically retarded by chloride ions using the $\mathrm{UV} / \mathrm{H}_{2} \mathrm{O}_{2}$ process. Several toxic AOX compounds were identified, which could be attributed to the involvement of chlorine radicals formed during the treatments. However, Fig. 4 shows that $\mathrm{AOX}$ values decreased gradually with reaction time in the $\mathrm{UV} / \mathrm{H}_{2} \mathrm{O}_{2}$ system and the effect of chloride ions seems to be of reduced significance for AOX formation. The effect of chloride ions on the AOX formation has already been observed for other different AOPs including $\mathrm{UV} / \mathrm{TiO}_{2}$ [26] and PMS-based AOPs [16]. High concentrations of chloride ions could increase PMS-based AOP degradation of 2,4,6trichlorophenol, but also lead to the formation of increased amounts of toxic aromatic chlorinated compounds, as Xu et al reported [15]. Yuan et al [26] also observed that 
the AOX values were proportional to the concentration of $\mathrm{Cl}^{-}$ions added to the solution during the $\mathrm{UV} / \mathrm{TiO}_{2}$ oxidation of azo dye-AO7.

AOX formation in the presence of $\mathrm{Cl}^{-}$can be depicted as follows (Eqs. (6)-(8), $\mathrm{R}$ presents the organic pollutants).

$$
\begin{aligned}
& \mathrm{SO}_{4}{ }^{--}+\mathrm{R} \rightarrow \mathrm{R}^{{ }^{+}}+\mathrm{SO}_{4}{ }^{2-} \\
& \mathrm{Cl}_{2}{ }^{\circ-} / \mathrm{Cl}^{\cdot}+\mathrm{R}^{\cdot} \rightarrow \mathrm{RCl} \rightarrow \mathrm{AOX} \\
& \mathrm{Cl}_{2} / \mathrm{HOCl}+\mathrm{R} \rightarrow \mathrm{RCl}+\mathrm{H}_{2} \mathrm{O} \rightarrow \mathrm{AOX}
\end{aligned}
$$

For the UV/PS system, the addition of $\mathrm{Cl}^{-}$was of low significance for the degradation rates, but it could result in a serious influence on AOX values. The AOX formation unambiguously indicated that using the degradation kinetics alone to evaluate the effect of chloride on a UV/PS system is not reliable. In addition, AOX only represents a fraction of the chlorinated organic compounds. They are considered to be recalcitrant and expected to be completely mineralized by a prolonged oxidative treatment. The AOX analysis supports the hypothesis that the UV/PS oxidation process will not be a favorable alternative for treatment of saline wastewater, since the increase of AOX compounds may result in an increased toxicity of the treated water. To test this hypothesis, acute toxicity assays were performed during UV/PS treatment.

\subsection{Toxicity test}

The toxicity of MCPs and their degradation products were evaluated using a luminescent bacteria assay. The toxicity is detected as luminescence inhibition. The higher the inhibition, the more toxic is the sample [38]. Data for this test are summarized in Table 2. Samples to test the toxicity of the reaction solution without any chlorophenols were also examined.

In a chloride-rich condition, the luminescence inhibition of the initial solution containing $0.2 \mathrm{mM} 4-\mathrm{CP}$ was about $56 \%$. The value increased to $96 \%$ at $60 \mathrm{~min}$ and 
$97 \%$ at $180 \mathrm{~min}$. In the absence of chloride, the luminescence inhibition of the initial 4-CP solution was $54 \%$, which increased to $96 \%$ after treatment for 60 min and remained at this value till $180 \mathrm{~min}$. This means that the acute toxicity of the 4-CP mixture increased with reaction time, independent of the presence of chloride. A similar trend can be observed for the oxidation of 2-CP and 3-CP. This trend may be attributed to the formation and accumulation of chlorinated oxidation intermediates, being more toxic than the parent compound. These findings are also supported by the chlorination data obtained from GC-MS and AOX analyses. In general, a complete mineralization of organic contaminants would decrease the toxicity to living beings $[40,41]$. In contrast, the presence of some oxidation products may lead to an increase in toxicity $[42,43]$.

The inhibition rates continued to increase up to nearly $100 \%$ after $180 \mathrm{~min}$ treatment in the UV/PS system. This coincided with the complete disappearance of MCPs as shown in Fig. 1. It is important to emphasize that the toxicity continued to increase despite the complete removal of the target pollutants MCPs. MCPs were possibly transformed to new products, which were more toxic and not completely mineralized. Obviously, the toxicity after MCPs complete degradation resulted from the intermediate oxidation products produced in the reaction solution.

The variation of acute toxicity has already been observed in other AOP systems such as $\mathrm{UV} / \mathrm{H}_{2} \mathrm{O}_{2}[2,44]$ or the Fenton reaction oxidation [2]. Karci et al [2] reported that during $\mathrm{H}_{2} \mathrm{O}_{2} / \mathrm{UV}-\mathrm{C}$ and photo-Fenton degradation of 2,4-dichlorophenol, the acute toxicity decreased with decreasing 2,4-dichlorophenol and increasing chloride release. Our previous study [44] showed the addition of $\mathrm{Cl}^{-}$had little influence on the toxicity of $\mathrm{UV} / \mathrm{H}_{2} \mathrm{O}_{2}$ solutions, and the toxicity of 2,4,6-trichlorophenol solution decreased with the reaction time. 


\section{Conclusions}

The results indicate that the impact of chloride addition $(0-300 \mathrm{mM})$ was of reduced significance for the degradation kinetics of MCPs, a significant influence on AOX formation was detected. Our present study provides a comprehensive understanding on PS-based AOPs (not limited to UV/PS). The result is that this process is not a favorable alternative for saline wastewater treatment due to the generation of toxic chlorinated products, undesirable AOX accumulation and enhanced acute toxicity. In addition, a complete removal of the target pollutant can not be as the sole standard to assess the applicability of AOPs. Additional parameters such as AOX content and toxicity are required, especially for saline wastewater. A possible degradation pathway for 4-CP under high salinity condition is proposed. Identification and quantification of all transformation byproducts, which are usually present in trace amounts, is complicate. Hence, a group parameter such as AOX may be informative while selecting the appropriate AOP. Nevertheless, it cannot provide information about the nature of the organohalogens in the treated water. Similarly, it is beneficial to examine the joint toxicity of degradation products and the remaining parent substrate. Therefore, a comprehensive assessment of kinetics, AOX and toxic effects should be carefully considered, while evaluating the applicability of an AOP for contaminant treatment.

\section{Acknowledgments}

This work was supported by the National Science Foundation of China (NSFC) (Nos. 21377023, 21677031), National Key Research and Development Program of China (2016YFC0400501/2016YFC0400509), Shanghai Pujiang Program and DHU Distinguished Young Professor Program. The authors also appreciate Prof. Wolfgang 
Sand from Duisburg-Essen University, Germany and the financial support from the Fundamental Research funds for Central Universities (15D311312). Z.H.W would like to thank the support of State Key Laboratory of Pollution Control and Resource Reuse Fund (PCRRF16006).

\section{Appendix A. Supplementary material}

Supplementary data associated with this article can be found, in the online version.

\section{References}

[1] Y.J. Jung, W.G. Kim, Y. Yoon, J.W. Kang, Y.M. Hong, H.W. Kim, Removal of amoxicillin by UV and UV/ $\mathrm{H}_{2} \mathrm{O}_{2}$ processes, Sci. Total Environ. 420 (2012) 160-167. [2] A. Karci, I. Arslan-Alaton, T. Olmez-Hanci, M. Bekbölet, Transformation of 2,4dichlorophenol by $\mathrm{H}_{2} \mathrm{O}_{2} / \mathrm{UV}-\mathrm{C}$, Fenton and photo-Fenton processes: Oxidation products and toxicity evolution, J. Photochem. Photobiol. A 230 (2012) 65-73.

[3] G.P. Anipsitakis, D.D. Dionysiou, Degradation of organic contaminants in water with sulfate radicals generated by the conjunction of peroxymonosulfate with cobalt, Environ. Sci. Technol. 37 (2003) 4790-4797.

[4] G.P. Anipsitakis, D.D. Dionysiou, M.A. Gonzalez, Cobalt-mediated activation of peroxymonosulfate and sulfate radical attack on phenolic compounds, Environ. Sci. Technol. 40 (2006) 1000-1007.

[5] N. Baycan, E. Thomanetz, F. Sengül, Influence of chloride concentration on the formation of AOX in UV oxidative system, J. Hazard. Mater. 143 (2007) 171-176.

[6] J. Kiwi, A. Lopez, V. Nadtochenko, Mechanism and kinetics of the OH-Radical intervention during Fenton oxidation in the presence of a significant amount of radical scavenger $\left(\mathrm{Cl}^{-}\right)$, Environ. Sci. Technol. 34 (2000) 2162-2168. 
[7] Z.H. Wang, R.X. Yuan, Y.G. Guo, L. Xu, J.S. Liu, Effects of chloride ions on bleaching of azo dyes by $\mathrm{Co}^{2+} / \mathrm{Oxone}$ regent: kinetic analysis, J. Hazard. Mater. 190 (2011) 1083-1087.

[8] J.E. Grebel, J.J. Pignatello, W.A. Mitch, Effect of halide ions and carbonates on organic contaminant degradation by hydroxyl radical-based advanced oxidation processes in saline waters, Environ. Sci. Technol. 44 (2010) 6822-6828.

[9] S.N. Ramjaun, R.X. Yuan, Z.H. Wang, J.S. Liu, Degradation of reactive dyes by contact glow discharge electrolysis in the presence of $\mathrm{Cl}^{-}$ions: kinetics and $\mathrm{AOX}$ formation, Electrochim. Acta 58 (2011) 364-371.

[10] M.C. Lu, J.N. Chang, C.P. Chang, Effect of inorganic ions on the oxidation of dichlorvos insecticide with Fenton's reagent, Chemosphere 35 (1997) 2285-2293.

[11] W.Z. Thang, C.P. Hung, 2,4-Dichlorophenol oxidation kinetics by Fenton's reagent, Environ. Technol. 17 (1996) 1371-1378.

[12] X.Y. Lou, Y.G. Guo, D.X. Xiao, Z.H. Wang, S.Y. Lu, J.S. Liu, Rapid dye degradation with reactive oxidants generated by chloride-induced peroxymonosulfate activation, Environ Sci Pollut Res 20 (2013) 6317-6323.

[13] J.M. Monteagudo, A. Durán, J. Latorre, A.J. Expósito, Application of activated persulfate for removal of intermediates from antipyrine wastewater degradation refractory towards hydroxyl radical, J. Hazard. Mater. 306 (2016) 77-86.

[14] K.H. Chan, W. Chu, Degradation of atrazine by cobalt-mediated activation of peroxymonosulfate: Different cobalt counteranions in homogenous process and cobalt oxide catalysts in photolytic heterogeneous process, Water Research 43 (2009) 25132521. 
[15] L. Xu, R.X. Yuan, Y.G. Guo, D.X. Xiao, Y. Cao, Z.H. Wang, J.S. Liu, Sulfate radical-induced degradation of 2,4,6-trichlorophenol: a de novo formation of chlorinated compounds, Chem. Eng. J. 217 (2013) 169-173.

[16] R.X. Yuan, S.N. Ramjaun, Z.H. Wang, J.S. Liu, Effects of chloride ion on degradation of Acid Orange 7 by sulfate radical-based advanced oxidation process: Implications for formation of chlorinated aromatic compounds, J. Hazard. Mater.196 (2011) 173-179.

[17] Y.G. Guo, J. Zhou, X.Y. Lou, R.L. Liu, D.X. Xiao, C.L. Fang, Z.H. Wang, J.S. Liu, Enhanced degradation of Tetrabromobisphenol $A$ in water by a UV/base/persulfate system: Kinetics and intermediates, Chem. Eng. J. 254 (2014) $538-544$.

[18] R.L. Johnson, P.G. Tratnyek, R.O. Johnson, Persulfate persistence under thermal activation conditions, Environ. Sci. Technol. 42 (2008) 9350-9356.

[19] G.J. Price, A.A. Clifton, Sonochemical acceleration of persulfate decomposition, Polymer 37 (1996), 3971-3973.

[20] G.P. Anipsitakis, D.D. Dionysiou, Radical generation by the interaction of transition metals with common oxidants, Environ. Sci. Technol. 38 (2004) 3705-3712. [21] M.G. Antoniou, A.A. Cruz, D.D. Dionysiou, Degradation of microcystin-LR using sulfate radicals generated through photolysis, thermolysis and e-transfer mechanisms, Appl. Catal. B 96 (2010) 290-298.

[22] Y. Yang, J.J. Pignatello, J. Ma, W.A. Mitch, Comparison of Halide Impacts on the Efficiency of Contaminant Degradation by Sulfate and Hydroxyl Radical-Based Advanced Oxidation Processes (AOPs), Environ. Sci. Technol. 48 (2014) 2344-2351. [23] J. Criquet, N. K.V. Leitner, Degradation of acetic acid with sulfate radical generated by persulfate ions photolysis, Chemosphere 77 (2009) 194-200. 
[24] T. K. Lau, W. Chu, N. J. D. Graham, The aqueous degradation of butylated hydroxyanisole by $\mathrm{UV} / \mathrm{S}_{2} \mathrm{O}_{8}{ }^{2-}$ : study of reaction mechanisms via dimerization and mineralization, Environ. Sci. Technol. 41 (2007) 613-619.

[25] I. Peternel, N. Koprivanac, I. Grcic, Mineralization of p-chlorophenol in water solution by AOPs based on UV irradiation, Enviro. Technol. 33 (2012) 27-36.

[26] R.X. Yuan, S.N. Ramjaun, Z.H. Wang, J.S. Liu, Photocatalytic degradation and chlorination of azo dye in saline wastewater: kinetics and AOX formation, Chem. Eng. J. 192 (2012) 171-178.

[27] M. Czaplicka, Photo-degradation of chlorophenols in the aqueous solution, J. Hazard. Mater. 134 (2006) 45-59.

[28] Y.G. Guo, X.Y. Lou, C.L. Fang, D.X. Xiao, Z.H. Wang, J.S. Liu, Novel photosulfite system: toward simultaneous transformations of inorganic and organic pollutants, Environ. Sci. Technol. 47 (2013) 11174-11181.

[29] European Standard EN 1485 H14, Water Quality Determination of Adsorbable Bound Halogens (AOX), 1996.

[30] S.J. Jiao, S.R. Zheng, D.Q. Yin, L.H. Wang, L.Y. Chen, Aqueous photolysis of tetracycline and toxicity of photolytic products to luminescent bacteria, Chemosphere 73 (2008) 377-382.

[31] F. Yuan, C. Hu, X. Hu, D. Wei, Y. Chen, J. Qu, Photodegradation and toxicity changes of antibiotics in UV and $\mathrm{UV} / \mathrm{H}_{2} \mathrm{O}_{2}$ process, J. Hazard. Mater. 185 (2011) $1256-1263$.

[32] C.J. Liang, Z.S. Wang, N. Mohanty, Influences of carbonate and chloride ions on persulfate oxidation of trichloroethylene at $20{ }^{\circ} \mathrm{C}$, Sci. Total Environ. 370 (2006) $271-277$. 
[33] H.V. Lutze, N. Kerlin, T. C. Schmidt, Sulfate radical-based water treatment in presence of chloride: Formation of chlorate, inter-conversion of sulfate radicals into hydroxyl radicals and influence of bicarbonate, Water Res. 72 (2015) 349-360.

[34] M. Bertelli, E. Selli, Reaction paths and efficiency of photocatalysis on $\mathrm{TiO}_{2}$ and of $\mathrm{H}_{2} \mathrm{O}_{2}$ photolysis in the degradation of 2-chlorophenol, J. Hazard. Mater. B138 (2006) 46-52.

[35] P. Boule, C. Guyon, J. Lemaire, Photochemistry and environment IVphotochemical behavior of monochlorophenols in dilute aqueous solution, Chemosphere 11 (1982) 1179-1188.

[36] J.Y. Zhao, Y.B. Zhang, X. Quan, S. Chen, Enhanced oxidation of 4-chlorophenol using sulfate radicals generated from zero-valent iron and peroxydisulfate at ambient temperature, Sep. Purif. Technol. 71(2010) 302-307.

[37] J. Zhou, J.H. Xiao, D.X. Xiao, Y.G. Guo, C.L. Fang, X.Y. Lou, Z.H. Wang, J.S. Liu, Transformations of chloro and nitro groups during the peroxymonosulfate-based oxidation of 4-chloro-2-nitrophenol, Chemosphere 134 (2015) 446-451.

[38] M. Krebel, H. Kusic, N. Koprivanac, J. Meixner, A. LoncaricBozic, Treatment of chlorophenols by UV-based processes: correlation of oxidation by-products, wastewater parameters, and toxicity, J. Environ. Eng.: ASCE 137 (2011) 639-649.

[39] R.X. Yuan, S.N. Ramjaun, Z.H. Wang, J.S. Liu, Concentration profiles of chlorine radicals and their significances in ${ }^{\circ} \mathrm{OH}$-induced dye degradation: Kinetic modeling and reaction pathways, J. Chem. Eng. J. 209 (2012) 38-45.

[40] R. Andreozzi, M. Canterino, R. Lo Giudice, R. Marotta, G. Pinto, A. Pollio, Lincomycin solar photodegradation, algal toxicity and removal from wastewaters by means of ozonation, Water Res. 40 (2006) 630-638. 
[41] H. Chaabane, E. Vulliet, F. Joux, F. Lantoine, P. Conan, J.F. Cooper, C.M. Coste, Photodegradation of sulcotrione in various aquatic environments and toxicity of its photoproducts for some marine micro-organisms, Water Res. 41 (2007) 1781-1789. [42] F. Bonnemoy, B. Lavedrine, A. Boulkamh, Influence of UV irradiation on the toxicity of phenylurea herbicides using Microtoxs test, Chemosphere 54 (2004) 11831187.

[43] A. Zertal, T. Sehili, P. Boule, Photochemical behaviour of 4-chloro-2methylphenoxyacetic acid: influence of $\mathrm{pH}$ and irradiation wavelength, J. Photochem. Photobiol. A: Chem. 146 (2001) 37-48.

[44] C.L. Fang, D.X. Xiao, W.Q. Liu, J. Zhou, Z.H. Wang, J.S. Liu, Enhanced AOX accumulation and aquatic toxicity during 2,4,6-trichlorophenol degradation in a Co(II)/peroxymonosulfate/ $\mathrm{Cl}^{-}$system, Chemosphere 144 (2016) 2415-2420. 

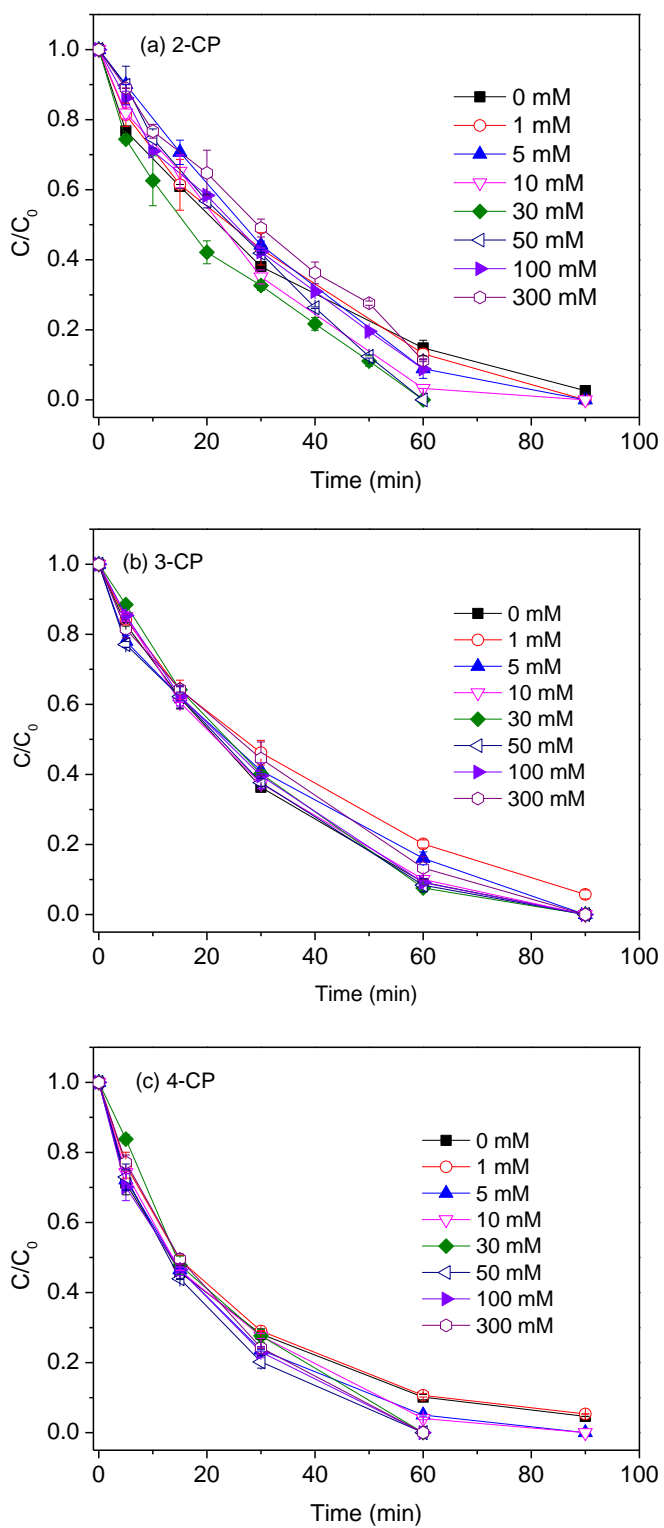

Fig. 1. The effects of different chloride concentrations on MCPs degradation during UV/PS treatment. Conditions: $[2-\mathrm{CP}]_{0}=[3-\mathrm{CP}]_{0}=[4-\mathrm{CP}]_{0}=0.2 \mathrm{mM},[\mathrm{PS}]_{0}=10 \mathrm{mM}$. 
$\mathrm{Cl}_{-\mathbf{S O}_{4}{ }^{2-}}^{\mathrm{OH}}$

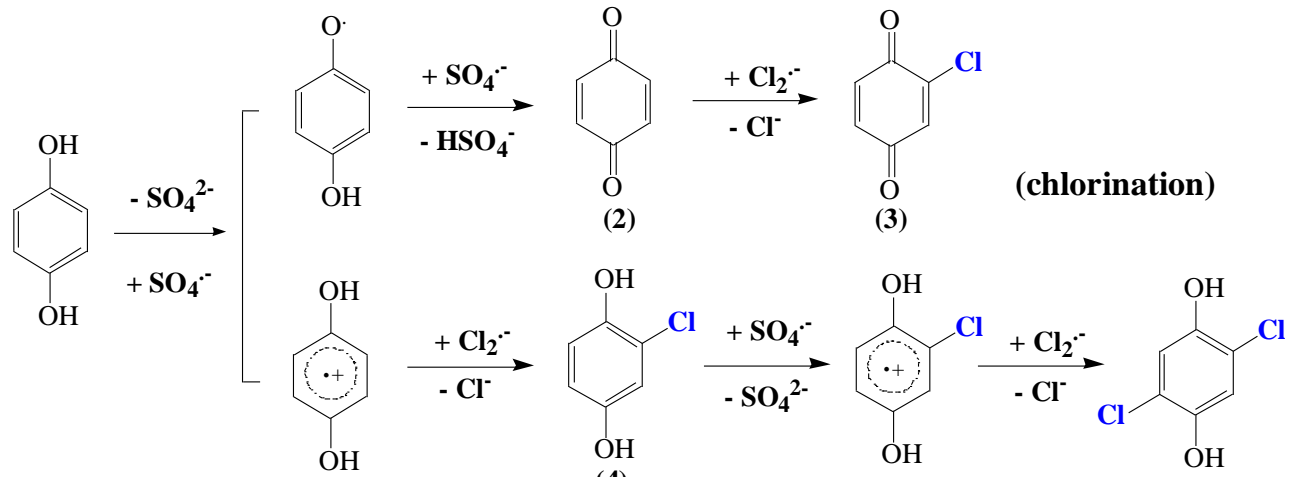

(4)

(5)

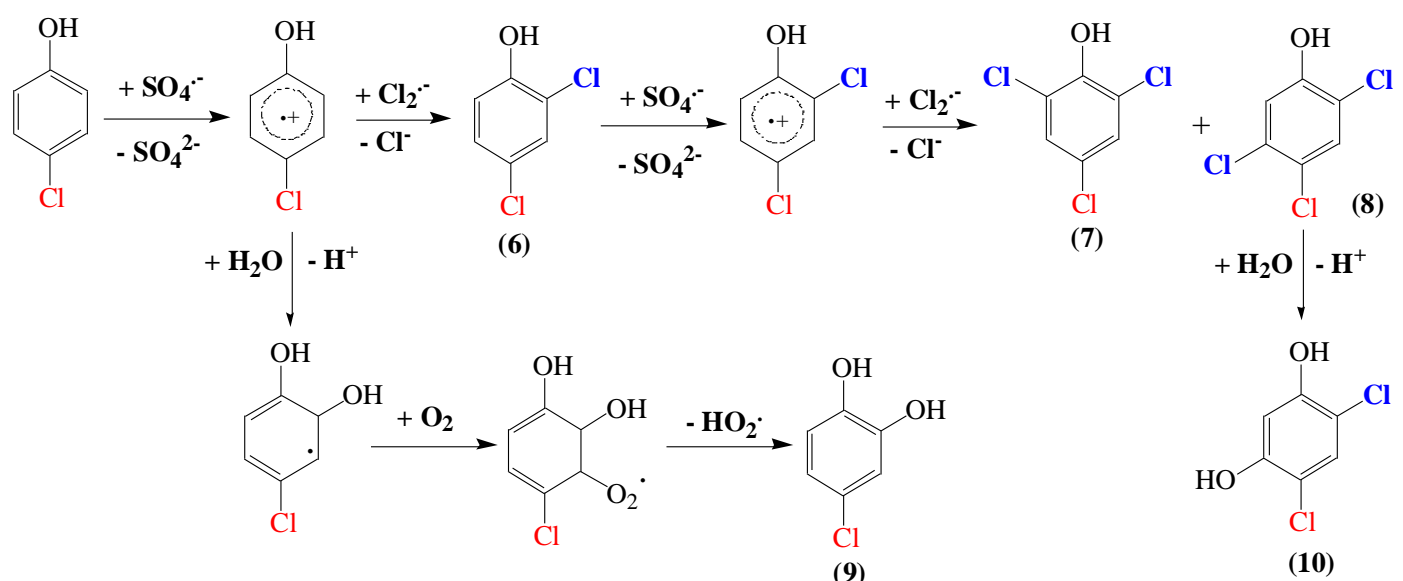

Fig. 2. The proposed pathway of $4-\mathrm{CP}$ in UV/PS/Cl system. Conditions: $[4-\mathrm{CP}]_{0}=0.2$ $\mathrm{mM},[\mathrm{PS}]_{0}=10 \mathrm{mM},\left[\mathrm{Cl}^{-}\right]_{0}=300 \mathrm{mM}$. 

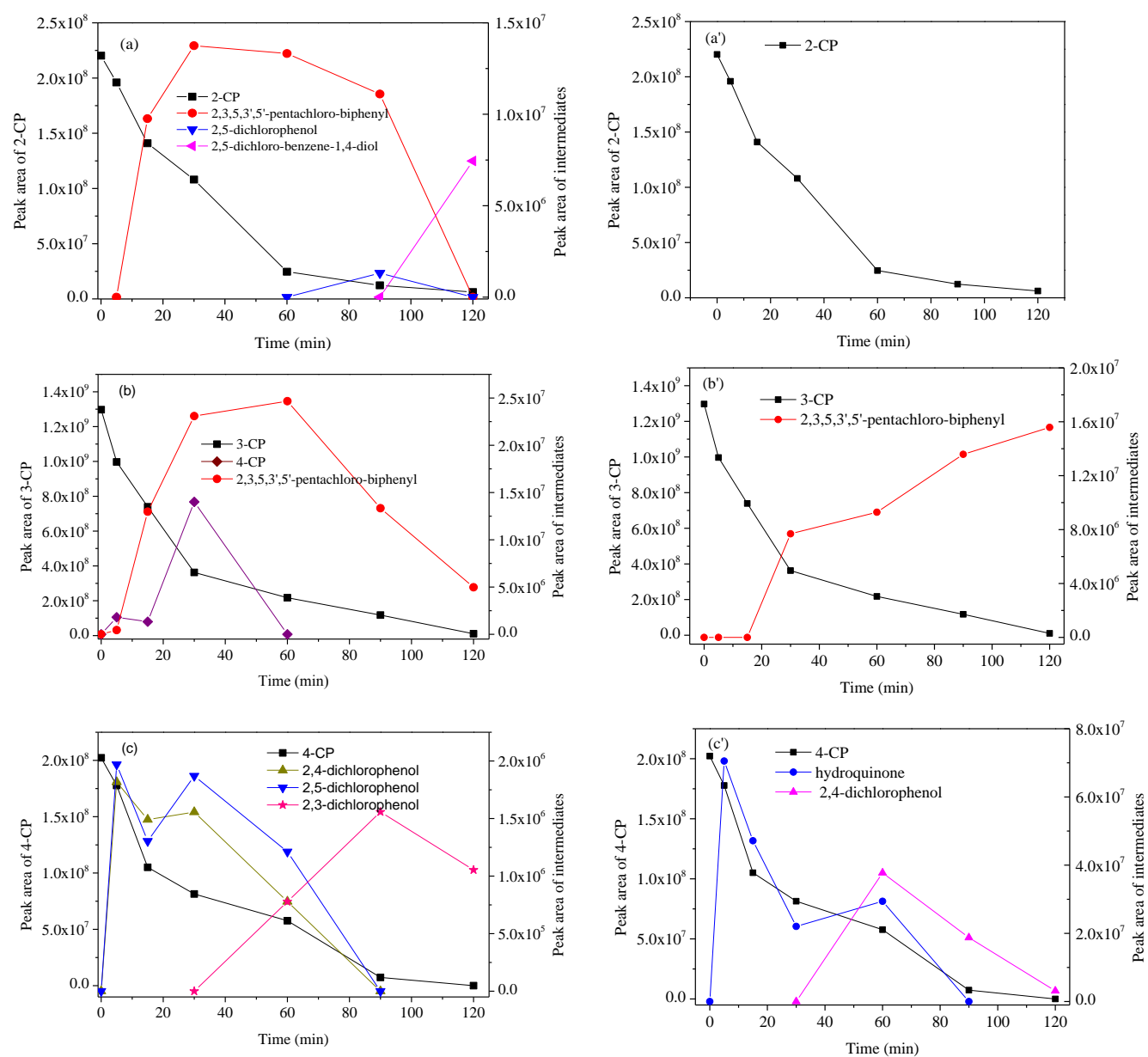

Fig. 3. Evolution of oxidation products identified by GC-MS analysis during UV/PS/Cl (a, b, c) and UV/PS (a', b', c') treatment of 2-CP, 3-CP and 4-CP. Conditions: $[2-\mathrm{CP}]_{0}=[3-\mathrm{CP}]_{0}=[4-\mathrm{CP}]_{0}=0.2 \mathrm{mM},[\mathrm{PS}]_{0}=10 \mathrm{mM},\left[\mathrm{Cl}^{-}\right]_{0}=300 \mathrm{mM}$. 


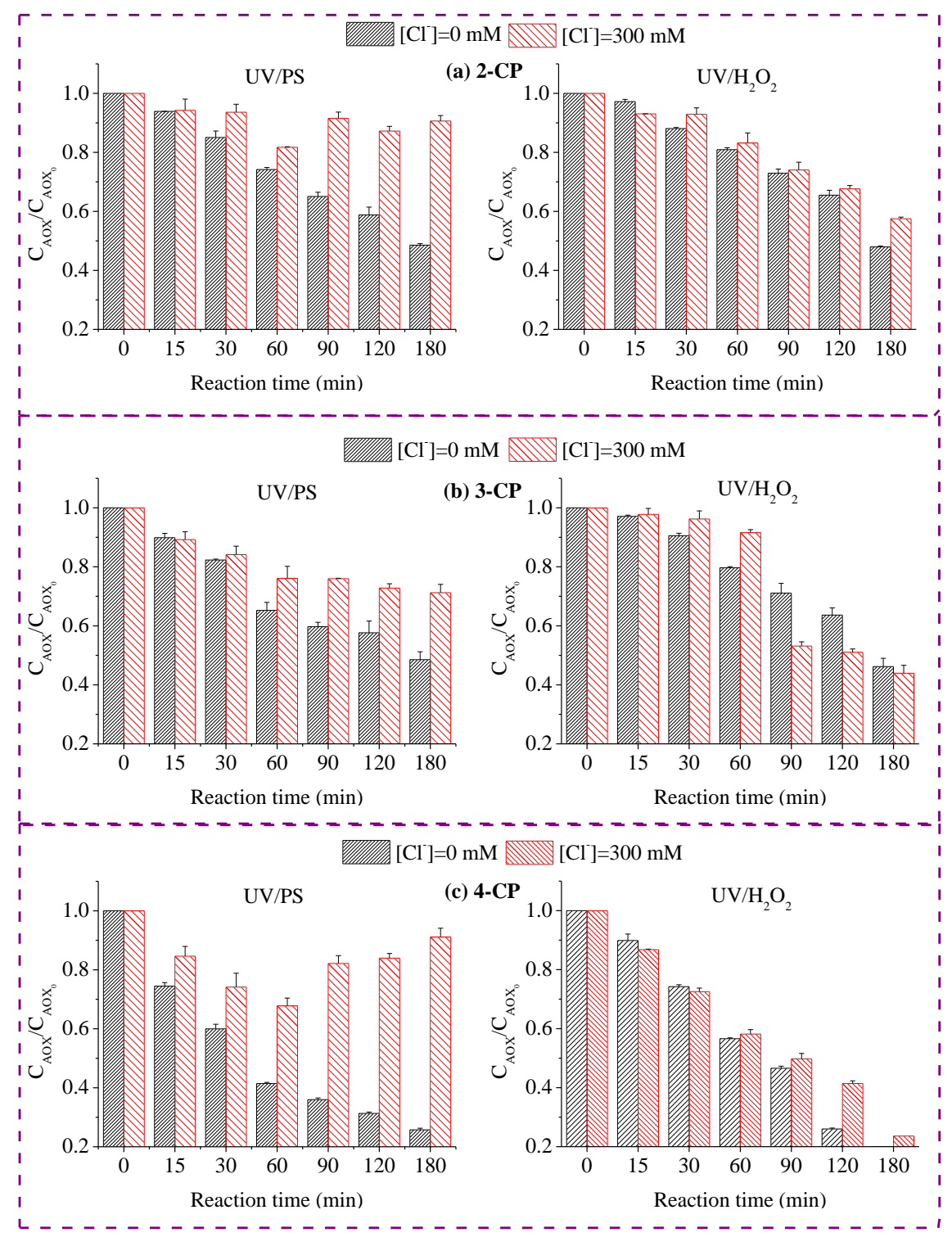

Fig. 4. Comparison of AOX formation in presence of chloride during UV/PS and $\mathrm{UV} / \mathrm{H}_{2} \mathrm{O}_{2}$ treatment of 2-CP, 3-CP and 4-CP. Conditions: $[2-\mathrm{CP}]_{0}=[3-\mathrm{CP}]_{0}=[4-\mathrm{CP}]_{0}$ $=0.2 \mathrm{mM},[\mathrm{PS}]_{0}=\left[\mathrm{H}_{2} \mathrm{O}_{2}\right]_{0}=10 \mathrm{mM},\left[\mathrm{Cl}^{-}\right]_{0}=300 \mathrm{mM}$. 
Table 1. All tentatively identified products by GC-MS during UV/PS degradation of 2-CP, 3-CP or 4-CP.

\begin{tabular}{|c|c|c|c|c|c|c|c|c|c|c|}
\hline \multirow{2}{*}{ Compound } & \multirow{2}{*}{ Structure } & \multirow{2}{*}{ Formula } & \multirow{2}{*}{$\begin{array}{c}\text { MS } \\
\text { match } \\
\text { value }^{\text {a }}\end{array}$} & \multirow{2}{*}{$\begin{array}{c}\text { MW } \\
(\mathrm{g} / \mathbf{m o l})\end{array}$} & \multicolumn{3}{|c|}{ UV/PS/Cl } & \multicolumn{3}{|c|}{ UV/PS } \\
\hline & & & & & $\begin{array}{l}2- \\
\text { CP }\end{array}$ & $\begin{array}{l}\text { 3- } \\
\text { CP }\end{array}$ & $\begin{array}{l}4- \\
\text { CP }\end{array}$ & $\begin{array}{l}2- \\
\text { CP }\end{array}$ & $\begin{array}{l}3- \\
\mathbf{C P}\end{array}$ & $\begin{array}{l}\text { 4- } \\
\text { CP }\end{array}$ \\
\hline $\begin{array}{c}\text { (P1) } \\
\text { 2-chlorophenol }\end{array}$ & & $\mathrm{C}_{6} \mathrm{H}_{5} \mathrm{ClO}$ & 98 & 128.56 & $\sqrt{ }$ & & $\sqrt{ }$ & $\sqrt{ }$ & & \\
\hline $\begin{array}{c}\text { (P2) } \\
\text { 3-chlorophenol }\end{array}$ & $\mathrm{HO}$ & $\mathrm{C}_{6} \mathrm{H}_{5} \mathrm{ClO}$ & 97 & 128.56 & $\sqrt{ }$ & $\sqrt{ }$ & $\sqrt{ }$ & $\sqrt{ }$ & $\sqrt{ }$ & $\sqrt{ }$ \\
\hline $\begin{array}{c}(\mathrm{P3}) \\
\text { 4-chlorophenol }\end{array}$ & & $\mathrm{C}_{6} \mathrm{H}_{5} \mathrm{ClO}$ & 98 & 128.56 & $\sqrt{ }$ & $\sqrt{ }$ & $\sqrt{ }$ & $\sqrt{ }$ & $\sqrt{ }$ & $\sqrt{ }$ \\
\hline $\begin{array}{c}(\mathbf{P 4}) \\
\text { Resorcinol }\end{array}$ & & $\mathrm{C}_{6} \mathrm{H}_{6} \mathrm{O}_{2}$ & $<90$ & 110.11 & & $\sqrt{ }$ & $\sqrt{ }$ & & $\sqrt{ }$ & $\sqrt{ }$ \\
\hline $\begin{array}{c}\text { (P5) } \\
\text { Hydroquinone }\end{array}$ & $\mathrm{HO}$ & $\mathrm{C}_{6} \mathrm{H}_{6} \mathrm{O}_{2}$ & 96 & 110.11 & & & $\sqrt{ }$ & & $\sqrt{ }$ & $\sqrt{ }$ \\
\hline $\begin{array}{c}\text { (P6) } \\
\text { 2,3-dichlorophenol }\end{array}$ & & $\mathrm{C}_{6} \mathrm{H}_{4} \mathrm{Cl}_{2} \mathrm{O}$ & $<90$ & 163.00 & & & & & & $\sqrt{ }$ \\
\hline $\begin{array}{c}(\text { P7) } \\
\text { 2,4-dichlorophenol }\end{array}$ & & $\mathrm{C}_{6} \mathrm{H}_{4} \mathrm{Cl}_{2} \mathrm{O}$ & 99 & 163.00 & & & $\sqrt{ }$ & & & $\sqrt{ }$ \\
\hline $\begin{array}{c}\text { (P8) } \\
\text { 2,5-dichlorophenol }\end{array}$ & & $\mathrm{C}_{6} \mathrm{H}_{4} \mathrm{Cl}_{2} \mathrm{O}$ & $<90$ & 163.00 & & & $\sqrt{ }$ & & & \\
\hline $\begin{array}{c}\text { (P9) } \\
\text { 2,6-dichlorophenol }\end{array}$ & & $\mathrm{C}_{6} \mathrm{H}_{4} \mathrm{Cl}_{2} \mathrm{O}$ & 99 & 163.00 & & & $\sqrt{ }$ & & & $\sqrt{ }$ \\
\hline $\begin{array}{c}(\mathbf{P 1 0}) \\
\mathbf{2 , 4 , 5 -} \\
\text { trichlorophenol }\end{array}$ & & $\mathrm{C}_{6} \mathrm{H}_{3} \mathrm{Cl}_{3} \mathrm{O}$ & $<90$ & 197.45 & & & & & & $\sqrt{ }$ \\
\hline (P11) & & $\mathrm{C}_{6} \mathrm{H}_{3} \mathrm{Cl}_{3} \mathrm{O}$ & 99 & 197.45 & & & $\sqrt{ }$ & & & \\
\hline $\begin{array}{c}\text { (P12) } \\
\text { 2-chloroquinone }\end{array}$ & & $\mathrm{C}_{6} \mathrm{H}_{3} \mathrm{ClO}_{2}$ & 91 & 142.54 & & & $\sqrt{ }$ & & & \\
\hline
\end{tabular}




\begin{tabular}{|c|c|c|c|c|c|c|c|c|c|c|}
\hline $\begin{array}{c}(\mathrm{P13}) \\
\text { 4-chlorobenzene- } \\
\text { 1,2-diol }\end{array}$ & & $\mathrm{C}_{6} \mathrm{H}_{5} \mathrm{ClO}_{2}$ & 90 & 144.56 & & & $\sqrt{ }$ & & & \\
\hline $\begin{array}{c}\text { (P14) } \\
\text { 2,5-dichloro- } \\
\text { benzene-1,4-diol }\end{array}$ & & $\mathrm{C}_{6} \mathrm{H}_{4} \mathrm{Cl}_{2} \mathrm{O}_{2}$ & 93 & 179.00 & & & $\sqrt{ }$ & & & \\
\hline $\begin{array}{c}\text { (P15) } \\
\text { 4,6-dichloro- } \\
\text { benzene-1,3-diol }\end{array}$ & & $\mathrm{C}_{6} \mathrm{H}_{4} \mathrm{Cl}_{2} \mathrm{O}_{2}$ & $<90$ & 179.00 & & & $\sqrt{ }$ & & & \\
\hline $\begin{array}{c}\text { (P16) } \\
\text { 3,6-dichloro- }\end{array}$ & & $\mathrm{C}_{6} \mathrm{H}_{4} \mathrm{Cl}_{2} \mathrm{O}_{2}$ & $<90$ & 179.00 & & & $\sqrt{ }$ & & & \\
\hline $\begin{array}{c}(\text { P17) } \\
\text { 2-chlorobenzene- } \\
\text { 1,4-diol }\end{array}$ & & $\mathrm{C}_{6} \mathrm{H}_{5} \mathrm{ClO}_{2}$ & $<90$ & 144.56 & & & $\sqrt{ }$ & & & \\
\hline $\begin{array}{c}(\text { P18 }) \\
\text { 2-chlorobenzene- } \\
\text { 1,3-diol }\end{array}$ & & $\mathrm{C}_{6} \mathrm{H}_{5} \mathrm{ClO}_{2}$ & $<90$ & 144.56 & & & $\sqrt{ }$ & & & \\
\hline (P19) & & & & & & & & & & \\
\hline $\begin{array}{c}2,3,5,3 ', 5 '- \\
\text { pentachloro- } \\
\text { biphenyl }\end{array}$ & $\mathrm{Cl} C \mathrm{Cl}$ & $\mathrm{C}_{12} \mathrm{H}_{5} \mathrm{Cl}_{5}$ & 90 & 254.27 & $\sqrt{ }$ & $\sqrt{ }$ & & $\sqrt{ }$ & $\sqrt{ }$ & $\sqrt{ }$ \\
\hline $\begin{array}{c}\text { (P20) } \\
\text { butane-1,4-diol }\end{array}$ & $\mathrm{HO}^{ح \mathrm{OH}}$ & $\mathrm{C}_{4} \mathrm{H}_{10} \mathrm{O}_{2}$ & 94 & 90.07 & $\sqrt{ }$ & $\sqrt{ }$ & $\sqrt{ }$ & $\sqrt{ }$ & $\sqrt{ }$ & $\sqrt{ }$ \\
\hline $\begin{array}{l}(\mathbf{P 2 1}) \\
\text { hydroxy-acetic } \\
\text { acid }\end{array}$ & & $\mathrm{C}_{2} \mathrm{H}_{4} \mathrm{O}_{3}$ & 93 & 76.02 & $\sqrt{ }$ & $\sqrt{ }$ & $\sqrt{ }$ & $\sqrt{ }$ & $\sqrt{ }$ & $\sqrt{ }$ \\
\hline
\end{tabular}

${ }^{\mathrm{a}}$ MS match value with the NIST library. 
Table 2. Acute biotoxicity assays of $2-\mathrm{CP}, 3-\mathrm{CP}$ and $4-\mathrm{CP}$ at different reaction times in the UV/PS system and UV/PS/Cl system. (All the toxicity experiments were conducted in triplicate)

\begin{tabular}{|c|c|c|c|c|}
\hline \multirow{2}{*}{\multicolumn{2}{|c|}{ Systems }} & \multicolumn{3}{|c|}{ Inhibition rate $(\%)$} \\
\hline & & \multirow{2}{*}{$\frac{\mathbf{0} \text { min }}{2.8 \pm 0.2}$} & \multirow{2}{*}{$\begin{array}{c}\mathbf{6 0} \text { min } \\
10.8 \pm 0.2\end{array}$} & \multirow{2}{*}{$\frac{180 \text { min }}{22.8 \pm 1.2}$} \\
\hline \multirow{2}{*}{$\begin{array}{l}\text { Blank } \\
\text { control }\end{array}$} & UV/PS & & & \\
\hline & UV/PS/Cl & $9.5 \pm 1.1$ & $12.9 \pm 0.5$ & $33.9 \pm 2.0$ \\
\hline \multirow{2}{*}{$\hat{y}^{\mathrm{OH}}$} & UV/PS & $14.2 \pm 4.2$ & $62.5 \pm 0.6$ & $89.8 \pm 0.4$ \\
\hline & UV/PS/Cl & $15.9 \pm 2.0$ & $76.0 \pm 1.2$ & $96.7 \pm 0.4$ \\
\hline \multirow{2}{*}{ (1) } & UV/PS & $12.8 \pm 1.3$ & $38.7 \pm 0.3$ & $69.1 \pm 0.8$ \\
\hline & UV/PS/Cl & $15.4 \pm 0.7$ & $34.0 \pm 0.6$ & $96.3 \pm 0.4$ \\
\hline \multirow{2}{*}{ HO } & UV/PS & $54.7 \pm 0.9$ & $96.4 \pm 0.1$ & $96.8 \pm 0.1$ \\
\hline & UV/PS/CI & $56.6 \pm 0.1$ & $96.9 \pm 0.1$ & $97.3 \pm 0.2$ \\
\hline
\end{tabular}




\section{Graphic Abstract}

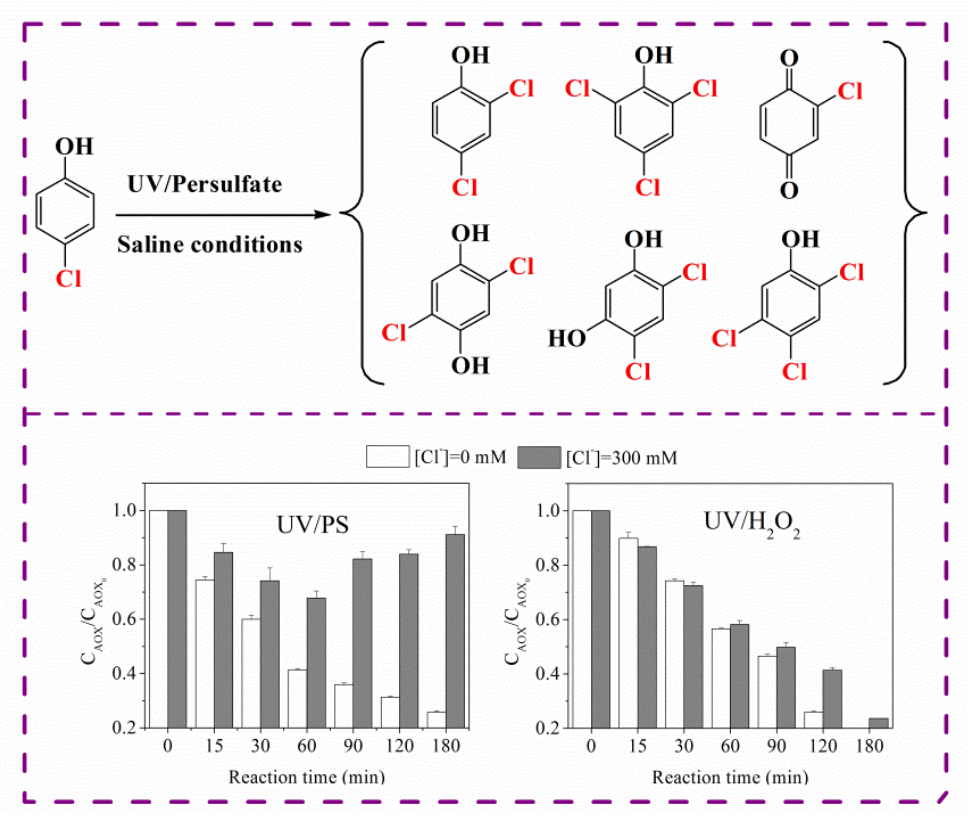

